\title{
Research on Crime Scene Investigation
}

\author{
Harathdra Sineagh \\ Forensic Science Laboratory, Kolkata, West Bengal (India)
}

\begin{abstract}
Crime scene investigation is a very important part of any investigation. It is the meeting point of science, logic and law. Crime scene investigation is a long, tedious process that involves useful documentation, photography or videography of the situation or condition on the scene and position of the evidence. The collection of any physical evidence that would possibly remove the darkness and illuminate what had happened and point to how and who did it. There may be no typical crime scene, there's no common frame of evidence and there is no typical investigative approach. Every crime scene investigation (CSI) unit handles the division between field work and lab work differently. All crime scene investigators are not forensic scientists. Some crime scene investigators work in the field only they collect the evidence and pass it to the forensic science laboratory for further examination and report. The major focus of this review is to propose practical approaches and guidelines to help forensic, and law enforcement professionals to deal with crime scene evidence to avoid contamination, degradation, and loss of the value of the evidence.
\end{abstract}

Keywords: Crime scene investigation, Physical evidence, Forensic science

\section{Introduction}

The investigation begins at the crime scene with the identification and recovery of physical evidence. After analysis and evolution of the results of recovered physical evidences and documents as well as the statements of witness's, it proceeds to presentation of the all findings to the court of law. From the first responders to the end - users of the information, all entire personnel should have an adequate understanding of the forensic process, like identification, recovery, collection, preservation, transportation and proper documentation to maintain the chain of custody. Crime scene investigation is a process aimed at recording the scene because it is the first encounter and indentifying and collecting all the physical evidences relevant to the solution of the case.

The scene of crime or place of occurrence is the actual site or location in which the incident took place. Generally the police personnel first reach at the crime scene and begin the investigation of the crime scene. The police personal who first attend the crime scene are called first responding officer (FRO). The first responding officer (FRO) properly protects the crime scene as well as the evidence of the crime scene. The entire investigation hinges on that first responding officer being able to properly identify, isolate, and secure the evidence (s). The crime scene can be secured by establishing a restricted boundary and it is done by using some types of crime scene tape, rope, or barrier for the purpose of securing the scene of crime and prevents evidence destruction. After secure the crime scene, the first responding officer (FRO) should maintaining the restrictions not to enter any non essential person to the crime scene.

During investigation of an incident may involve one or more place of occurrences. A primary crime scene as well as several secondary or tertiary crime scenes may be involved at another location. All the locations (it may be indoor, outdoor or car etc.) where the incident has occurred or recovered the evidence of that crime and connected to a particular incident all of these places are scene of crime. Basically, a crime scene is that place (s) where the incident has occurred or evidence of that crime may be recovered. Crime scene is not only the location where the crime took place. The place (s) where the related evidence may be located or recovered of a particular crime it is also a crime scene of that case. During investigation all of these crime scene should examine properly for unearth the actual truth of the incident. Each crime scene is unique and with experience a successful crime scene investigator uses this logical and systematic approach, the investigator will be able to make a successful conclusion to investigate even the most challenging crime scene. Crime scene investigation is a scientific process which includes documentation (including measurements and photography) collection and packing of physical evidence and finally reconstruction of crime scene. The Chain of custody of the evidence should strictly maintain during crime scene investigation.

The first responding officer, generally a police officer, plays a significant role in the entire crime scene investigation process. The initial responsibility of the police officer is to preserve the integrity of the crime scene and the evidence. The police officer is also responsible for the early documentation of crime scene and all its evidences. "In most of the cases, since the first responders are non - forensic personnel, adequate training on handling of evidence at SOC is crucial to successfully carry out these activities. "The first responding officer has to do some basic recovery procedures before the arrival of the crime scene investigators, if there's a risk of the evidence being destroyed, lost or contaminated. In situations where there's no prospect for the crime scene to be processed by crime scene investigators, the responsibilities of the first responding officer might need to be extended beyond preservation and documentation.

\subsection{Principles of Forensic Science}

The principles of forensic science refer to the disciplines and methods of science in evidence analysis to answer some questions. These principles of forensic science have an impact on criminal proceedings which start from the investigation of a crime scene to the conviction of an accused in the courts of Law. The principles of forensic science which are very important in criminal investigation are as follows: 


\subsubsection{Principles}

The laws and principles of all the natural sciences are the bases of forensic science. In addition, it has developed its own principles with the passage of times and experience.

\subsubsection{Law of individuality}

"Every object, natural or man - made, has an individuality which is not duplicated in any other object". This law has been established in several fields and fingerprints are the most common among them. Millions and Billions of fingerprints have been studied and yet not one fingerprint has matched with others whether it's of twins or two fingers of the individual. Any two objects like seeds, twins, or man made objects such as currency notes, coins, laptops, suits, shoes, typewriters, etc. they may seem similar to each other yet a unique characteristics are always present between them.

\subsubsection{Principle of exchange}

The French scientist Edmond Locard, a pioneer in forensic science and criminology, formulated the basic principle of forensic science "Every contact leaves a trace". The principle holds that the preparatory of a crime will bring something in to the crime scene and leave with something from it.

\subsubsection{Law of progressive change}

"Everything changes with the passage of time". The rate of change varies tremendously with different objects. Its impact on forensic science is immense. For example, the body of the victim starts decomposing with the passage of time, sample of blood also degrades in a period of time, fingerprint, foot impression, and tire marks also start to change/destroy rapidly due to weather, presence of human/animals in the span of time, if the crime scene is not managed properly in time.

\subsubsection{Principle of comparison}

The principle of comparison states that "Only the like can be compared". It emphasizes the necessity of providing like samples and specimens for comparison with the questioned items. For example, if in a case recovered some fingerprint from the crime scene, and then required to send some fingerprints only for comparison, it will be unnecessary to send a plaster cast of a footprint for comparisons.

\subsubsection{Principle of analysis}

This principle state that, "the analysis can be no better than the sample analyzed". This principle indicates that improper sampling and contamination of evidence may mislead the investigation and render the best analysis useless. The principle highlights the necessity of correct sampling and correct packing for effective analysis and results.

\subsubsection{Law of probability}

This principle says that "All identifications, definite or indefinite, are made, consciously or unconsciously, on the basis of probability". It determines the probability that a particular event will occur in a certain way out of the total number of times an event may occur or fail to occur with equal benefit. For example, in a case, a six - fingered left hand print with cut marks on the palm has been recovered at the crime scene. The suspected person also has six fingers in his left hand with cut marks on the palm. So, there is a high chance that the person may be involved in that incident. The probability of that impression being of another person will be 1 in millions and the identity of that unknown impression is established.

\subsubsection{Law of circumstantial facts}

This principle state that "Facts do not lie but men can lie and do". Facts cannot be wrong, it cannot lie, and it cannot be wholly absent. Therefore the importance of circumstantial facts is good for oral evidence. For example, a armed force is detailed in the duty register his night duty from $8 \mathrm{pm}$ to the next day at 4 am morning. He took his duty at $8 \mathrm{pm}$. During his duty period, he secretly slips out of the unit at night and kills a person, and returned back secretly to join his duty on time. In the matter of circumstantial evidence, he can prove his presence in the unit in his duty period and escape the punishment.

So, forensic science is the scientific discipline that recognizes, identifies, distinguishes, and evaluates physical evidence through the application of its principles and methods of natural science for the purpose of administration of criminal justice.

\subsection{Protection of Crime scene}

The most important aspect of collecting and preserving evidence is to protect the crime scene. The crime scene is required to protect strongly until all evidence is recorded and collected from the crime scene to avoid contamination and maintain the integrity of the evidence. The successful prosecution of the case may depend on the condition of the physical evidence at the time of its collection and position of the evidence. The protection of the crime scene begins with the arrival of the first responder (generally police officer) at the scene of crime. Enter and exit routes should be examined carefully. The first responder should take control of the crime scene and determine the extent to which the scene is protected. Information regarding any change/disturbance should be obtained from persons who entered the scene before the arrival of the first responder or investigating officer, to ascertain the actual condition of the crime scene and position of the evidences. The crime scene and any other area that may recover valuable evidence should be closed to prevent further disturbance of the scene and contamination of potential physical sources. Unauthorized persons should not be allowed to enter the crime scene and those who enter/leave the crime scene should keep a record.

\subsection{Important issues to view while search $\&$ collection of material evidence}

i) Relevancy: Relevance is the concept of one topic being connected to another topic in a way that makes it useful to consider the second topic when considering the first. [https: //en. wikipedia. org/wiki/Relevance]. The meaning of "relevance" in U. S. law is reflected in Rule 401 of the Federal Rules of Evidence. That rule defines relevance as "having any tendency to make the existence of any fact that is of consequence to the determinations of the action more probable or less probable than it would be without the evidence." 
ii) Continuity: The continuity of evidence is often referred to as the 'chain of evidence' which is simple terms is the way the evidence has been handled from the moment that it is found, seized, or produced to the point that it is presented in court as an exhibit. Where the item was placed after it was seized. Continuity of evidence is the documentation of all information, step by step chronologically related to the collected evidence connected with a particular case maintained properly without breaking the chain of custody from the crime scene to the courtroom. From the first responders to the end - users of the information, all entire personnel should have an adequate understanding of the forensic process, like identification, recovery, collection, preservation, transportation, and proper documentation to maintain the chain of custody.

iii) Purity: The state of not being mixed with anything else.

iv) Integrity: Protecting the integrity of evidence collected is vital in law enforcement. If the integrity of the evidence is in doubt, its use in legal proceedings could be jeopardized, possibly allowing a guilty person to escape prosecution. Evidence is admissible in court only if the rules have been followed. [https: //aceproject. org/ace en/topics/ei/eie/eie03/eie03d]

All evidence materials should be sealed by the authorized personals before the witness.

\subsection{The Chain of Custody}

It is the written records of all of the individuals who maintained unbroken control over the items of evidence. The chain of custody must account for the seizure, storage, transfer and condition of the evidence. It establishes the proof that the items of evidence collected at the crime scene is the same evidence that is being presented in a court of law. The chain of custody is absolutely necessary for admissible evidence in court.

\subsubsection{To Safeguard The Chain of Custody:}

- Limit the number of individuals handling evidence.

- Confirm that all names, identification numbers, and dates are listed on the chain of custody documents.

- Ensure that all evidence packaging is properly sealed and marked prior to submission.

- Obtain signed or otherwise secure receipts upon transfer of evidence.

\subsection{Physical Evidence}

There are two types of evidence used to resolve an issue that can be divided into two areas. Testimonial evidences and physical evidence. Any witnessed accounts of an incident would represent testimonial evidence. The term "physical evidence" would refer to any material items that would be present at the scene of the crime. These items would be presented in a matter or incident to prove or disprove the facts of the issue in the court of law. The collection of physical evidence from the Crime scene is very important in the interest of establishing the following noted information.

- The physical evidence may prove that a crime has been committed.
- The Establish any key elements of an offence.

- Establish the actual place of occurrence.

- Link the suspect with the scene of crime.

- Link the suspect with the victims.

- Link the victim with the scene of crime.

- Link the suspect and victim with materials evidence.

- Establish the identity of a suspect or victim.

- Corroborate verbal witness testimony with the crime and crime scene.

- Acquit the innocent from the case.

\subsection{Types of Evidence}

- Impressions evidence: Include fingerprints, footwear, bare foot impression, tool marks, fabric impressions, tire marks and bite marks etc.

- Biological evidence: includes blood, semen, Saliva, vomit, body fluids, hair, nail scrapings, blood stain patterns etc

- Trace Evidence: Includes gun shot residues, arson accelerant, paint, glass and fibers etc.

- Firearms: includes weapons, gun powder patterns, projectiles, casings, pellets, fragments, wadding and cartridges etc.

- Electronics evidence: Includes computer, Laptop, CCTV, device, camera, CD/DVD, mobile, wire etc.

- Documentary Evidence: Includes Suicide notes, letters, markings, books, handwriting, Register, book, file, bill, letter, form, property document, photographs etc.

- Chemical Evidence: Includes Chemical materials, burning substances, explosive substances etc.

- Digital evidence: Digital devices, Electronic device messages, voice calls, Random calls, kidnapping calls, images etc.

- Tool: Knife, spade, rod, hammer, crowbar, etc.

- Miscellaneous: Button, brick, Cigarettes butt, ash, soil etc

\subsection{Crime Scene Searching Methods}

Identification and recovery of physical evidence is the main part of crime scene investigation. In this point of view, appropriate searching method (s) should necessary to apply to those types of crime scenes. There are a number of search patterns that may be followed in the interest of investigation of the crime scene. Some of them as are follows: -

\subsubsection{Strip Method}

Whole area to be search and divided into a convenient number of strips. Each strip is examined carefully one after another. The process continues until the searchers cover the entire area.

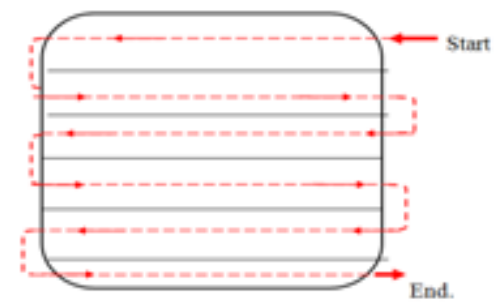




\subsubsection{Spiral method}

The searchers start from one end (a point of outside the area) of the crime scene move along with path of the spiral till they reached the centre of the crime scene.

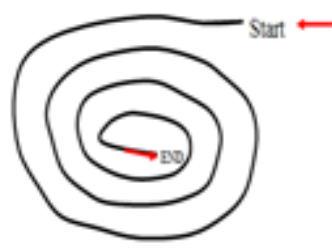

\subsubsection{Zone or quad method}

The crime scene is divided into several zones and each zone is examined in turn. The big square is then conveniently subdivided into small square and search each small square carefully.

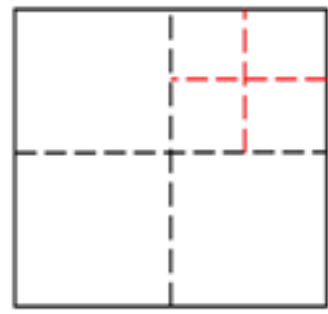

\subsubsection{Grid Method}

In the grid method, the searcher begins like a strip search. After completing the search by horizontal lanes, he searches back at right angles to the original strip. This search method from two different angles helps in the recovery of evidence which may be missed in simple strip method.

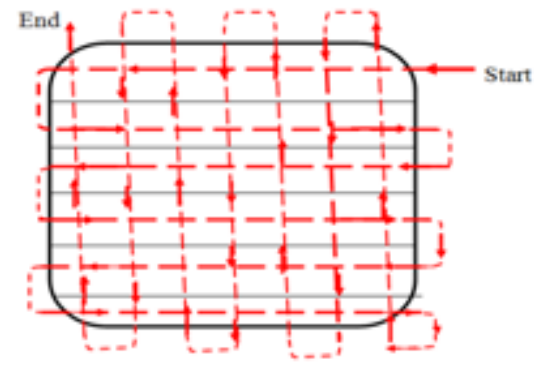

\subsubsection{Pie or Wheel method}

In this search method, the area is marked as circle or divided into pie slices or sections of a wheel, usually six in number. Crime scene searchers start from the centre point and proceed to travel outwards along straight lines or rays. Repeat the process several times depending on the size of the area.

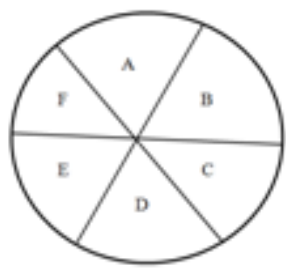

\subsection{Photography of the scene of crime}

After the preliminary observation of the crime scene, it should be recorded carefully by photography/sketching. Both videography and still photographs of the crime scene should be taken systemically. The photographs of any physical evidence like fingerprints, footprints, blood spatters, bullet holes, hair, fiber, etc. are essential for the examination and assessment of the importance of the evidence. The overall, medium, and close - up views of the scene as well as the evidence should be photographed successively with suitable scale or other size determination devices whenever applicable. The photographs should be taken from eye level when feasible so that they exhibit the scene, as it would be observed by the normal view. The physical clues should be photographed in place before its collection and packaging using a size determination device if necessary.

\subsection{Sketching of the scene of crime}

Sketch is the whole picture of the crime scene which show the distribution of the evidentiary clue at the crime scene. The sketch is convenient to appreciate the evidence at crime scene, the nature of the crime and the modus operandi of the commission of the crime. The sketch provides ideal, simple and easily intelligible mode to understand the place of occurrence. Supplement the other mode of recording the crime scene by videography, photography and written inspection report.

Primary sketch contain the following information.

Case reference: FIR no with date and section, Police station, District, and place of occurrence.

Nature of the crime: Murder, Dacoit,, Theft, Burglary etc. Name and signature of the investigating officers who prepared the rough sketch map of the crime scene.

Indicate the North by arrow head. Measurement table and index and proper labeling.

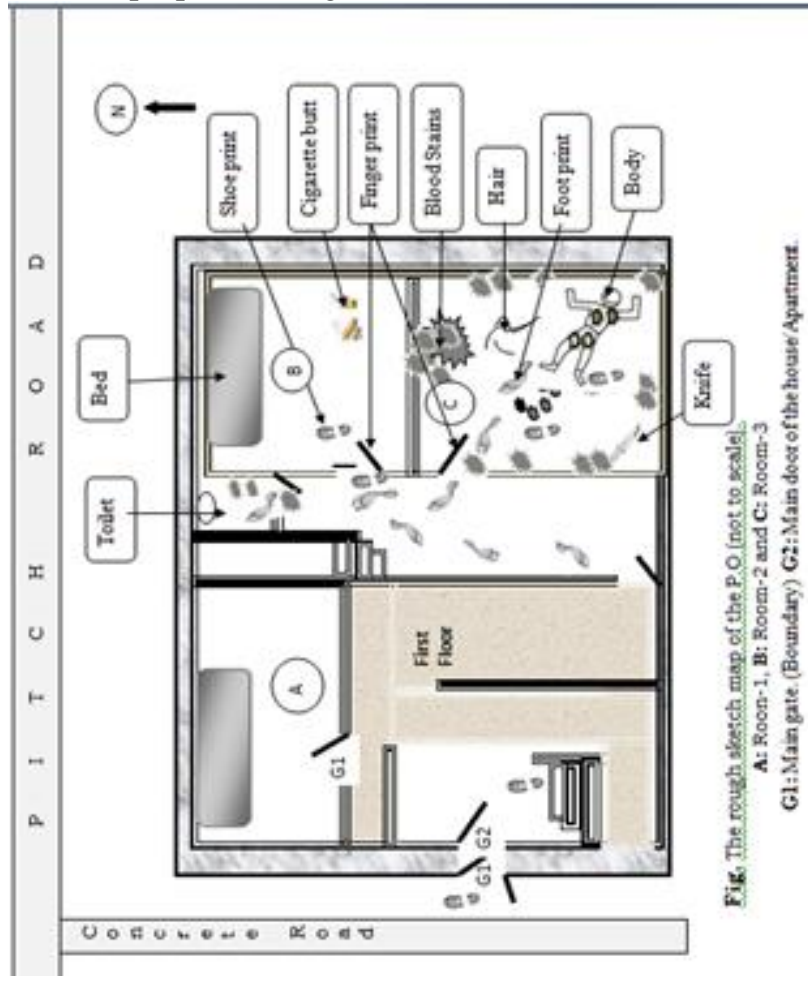


Table 1: Collection methods and packing of different evidences at the crime scene

\begin{tabular}{|c|c|c|c|}
\hline Sample & Collection Method & Packing and preservation & Precaution \\
\hline & \multicolumn{2}{|l|}{ Wet Blood } & \\
\hline Liquid Blood & $\begin{array}{l}\text { In EDTA vial/ tube or transfer on cotton } \\
\text { gauze cloth or collect on FTA Card. }\end{array}$ & $\begin{array}{l}\text { Air dry and keep in paper } \\
\text { envelope. }\end{array}$ & $\begin{array}{l}\text { Use of disposable syringe for collection } \\
\text { of blood in the EDTA vial/tube or FTA } \\
\text { card. Do not handle sample with bare } \\
\text { hand. }\end{array}$ \\
\hline Wet clotted blood & $\begin{array}{l}\text { Collect in sterile tube and add equal } \\
\text { volume of normal saline solution or } \\
\text { transfer in to cotton gauze cloth. }\end{array}$ & $\begin{array}{l}\text { Air dry and keep in paper } \\
\text { envelope. }\end{array}$ & Do not handle sample with bare hand. \\
\hline $\begin{array}{l}\text { Wet Clothing of victim } \\
\text { and suspect (s) }\end{array}$ & $\begin{array}{l}\begin{array}{l}\text { Thoroughly air dried at room temperature } \\
\text { and collect whole sample or cuttings with } \\
\text { control. }\end{array} \\
\end{array}$ & $\begin{array}{l}\text { Pack separately in paper } \\
\text { envelope or paper bag. }\end{array}$ & $\begin{array}{l}\text { Never try to pack the cloths dry or wet } \\
\text { in air tight container or polythene bag. }\end{array}$ \\
\hline $\begin{array}{l}\text { Blood stained Objects } \\
\quad \text { (such as knife) }\end{array}$ & $\begin{array}{c}\text { Thoroughly air dried at room temperature } \\
\text { and collect. }\end{array}$ & $\begin{array}{c}\text { Packed the item in paper } \\
\text { envelope/bag or cotton cloth } \\
\text { depending on the size of the } \\
\text { object. }\end{array}$ & Do not handle evidence with bare hand. \\
\hline $\begin{array}{c}\text { Blood Crust/ } \\
\text { Stain/Spatter Crime } \\
\text { scene unmovable } \\
\text { surface floor, wall etc. }\end{array}$ & $\begin{array}{l}\text { Scrap the crust onto paper with scalpel or } \\
\text { transfer onto a moistened clean cotton } \\
\text { gauze cloth by rubbing against the stain. }\end{array}$ & $\begin{array}{c}\text { Air dry and pack in paper } \\
\text { envelope. Collect proper } \\
\text { negative control from the } \\
\text { adjacent area. }\end{array}$ & Never use polythene bag for packing. \\
\hline \multirow[t]{2}{*}{$\begin{array}{c}\text { Blood Stain on } \\
\text { Weapon and other } \\
\text { small movable object. }\end{array}$} & $\begin{array}{c}\text { Allow the stain to dry and collect the } \\
\text { whole item. }\end{array}$ & $\begin{array}{l}\text { Pack in paper envelope and } \\
\text { keep in at room temperature. }\end{array}$ & $\begin{array}{l}\text { Never use polythene bag for packing. } \\
\text { Never forwarded Loaded firearms. }\end{array}$ \\
\hline & \multicolumn{2}{|c|}{ Dried blood stain and others body fluid. } & \\
\hline $\begin{array}{l}\text { Blood stained on } \\
\text { Vehicle, carpet, wall } \\
\text { paper, wooden object } \\
\text { etc }\end{array}$ & $\begin{array}{c}\text { Cut the stain area. Collect the negative } \\
\text { control cutting as control from adjacent } \\
\text { area. }\end{array}$ & $\begin{array}{l}\text { Allow to dry in room } \\
\text { temperature or shade. Pack } \\
\text { each cutting separately. }\end{array}$ & $\begin{array}{l}\text { Always documented the stains pattern } \\
\text { properly before removing. Do not mix } \\
\text { stains from different location. Collect } \\
\text { scraps of different spot in separate } \\
\text { packets. }\end{array}$ \\
\hline $\begin{array}{l}\text { Dried blood stained on } \\
\text { Object or crime scene. }\end{array}$ & $\begin{array}{l}\text { Collect the samples with sterile cotton } \\
\text { cloth swab. }\end{array}$ & $\begin{array}{c}\text { Air dry the swab and pack in } \\
\text { paper envelope. }\end{array}$ & Do not handle evidence with bare hand. \\
\hline Semen stain & $\begin{array}{l}\text { Collect the samples with sterile cotton } \\
\text { cloth swab. }\end{array}$ & $\begin{array}{l}\text { Air dry the swab and pack in } \\
\text { paper envelope }\end{array}$ & Do not handle evidence with bare hand. \\
\hline Saliva & $\begin{array}{c}\text { Collect the samples with sterile cotton } \\
\text { cloth swab. }\end{array}$ & $\begin{array}{l}\text { Air dry the swab and pack in } \\
\text { paper envelope }\end{array}$ & Do not handle evidence with bare hand. \\
\hline Urine & $\begin{array}{l}\text { The liquid urine sample is collected using } \\
\text { syringe and dried urine sample is } \\
\text { collected using sterile Cotton cloth swab. }\end{array}$ & $\begin{array}{l}\text { Air dry the swab and pack in } \\
\text { paper envelope }\end{array}$ & Do not handle evidence with bare hand. \\
\hline \multirow[t]{2}{*}{$\begin{array}{l}\text { Fragmented } \\
\text { Tissue/organ. }\end{array}$} & $\begin{array}{c}\text { Tissue/ Organ should be placed in a clean } \\
\text { container having normal saline. }\end{array}$ & $\begin{array}{l}\text { Use thermocol box stuffed } \\
\text { with ice/coolant pack. }\end{array}$ & Never add any fixatives like formalin. \\
\hline & \multicolumn{2}{|c|}{ Others evidences } & \\
\hline Bone/Teeth & $\begin{array}{c}\text { Preserve at least two intact bones, } \\
\text { reference Femur, Tibia, humerus, Teeth } \\
\text { (Molar 2-3) }\end{array}$ & $\begin{array}{c}\text { Allow to dry completely in air } \\
\text { and pack in paper packet / } \\
\text { envelope. }\end{array}$ & $\begin{array}{l}\text { Completely burnt bones are not useful } \\
\text { for forensic test. }\end{array}$ \\
\hline Hair \& Fiber & $\begin{array}{c}\text { Use tweezers/forceps during collection. } \\
\text { Collect reference samples from the victim } \\
\text { and suspect } 50 \text { - } 100 \text { standard hair should } \\
\text { be collected. }\end{array}$ & Pack in paper envelope. & Never wash the recovery hair. \\
\hline Firearms & $\begin{array}{l}\text { Pick up the gun with down position the } \\
\text { barrel of the Firearm }\end{array}$ & Pack in paper box & $\begin{array}{l}\text { Never wash the recovery firearms. Do } \\
\text { not handle evidence with bare hand. } \\
\text { Never forwarded Loaded firearms. }\end{array}$ \\
\hline $\begin{array}{l}\text { Bullet and cartridge } \\
\text { case. }\end{array}$ & $\begin{array}{l}\text { The fired bullet or empty cartridge } \\
\text { collected by forceps }\end{array}$ & Pack in paper box & $\begin{array}{l}\text { Never wash the recovery firearms. Do } \\
\text { not handle evidence with bare hand. }\end{array}$ \\
\hline GSR & $\begin{array}{l}\text { The GSR particles on the hand and } \\
\text { firearms can be collected by tape lifting } \\
\text { and swabbing method. }\end{array}$ & $\begin{array}{c}\text { Airs dry the GSR particles and } \\
\text { pack the item in separate paper } \\
\text { bag. }\end{array}$ & Do not handle evidence with bare hand. \\
\hline $\begin{array}{l}\text { Glass, Paint and other } \\
\text { trace evidence. }\end{array}$ & $\begin{array}{c}\text { Use tweezers/forceps during collection. If } \\
\text { required, Scrap the crust of paint onto } \\
\text { paper with scalpel. }\end{array}$ & $\begin{array}{l}\text { Pack in paper envelope or } \\
\text { suitable plastic container. }\end{array}$ & Do not handle evidence with bare hand. \\
\hline $\begin{array}{l}\text { Latent prints } \\
\text { (This type of prints are } \\
\text { not visible our naked } \\
\text { eyes, it required to } \\
\text { develop before } \\
\text { collection) }\end{array}$ & $\begin{array}{c}\text { After develop the print using Powder } \\
\text { methods like magnetic brush, white } \\
\text { powder, black powder, fluorescent } \\
\text { powder method and Chemical methods } \\
\text { like Ninhydrin method, silver chloride } \\
\text { method, iodine fuming method etc. and } \\
\text { then Collect the prints using Photography } \\
\text { and Tape lifting method. }\end{array}$ & Pack in paper box or envelope. & Do not handle evidence with bare hand. \\
\hline Patent prints & These types of prints are collected usually & Pack in paper box or envelope. & Do not handle evidence with bare hand. \\
\hline
\end{tabular}




\begin{tabular}{|c|c|l|l|}
\hline $\begin{array}{c}\text { It is visible through our } \\
\text { naked eyes. }\end{array}$ & $\begin{array}{c}\text { by photography method, lifting method } \\
\text { and tracing method. }\end{array}$ & & \\
\hline $\begin{array}{c}\text { Plastic prints } \\
\begin{array}{c}\text { This type of prints are } \\
\text { found in 3D condition }\end{array}\end{array}$ & $\begin{array}{c}\text { They are usually collected by using } \\
\text { plaster of parries or dental stone for } \\
\text { casting and Photographic methods. }\end{array}$ & Pack in paper box or envelope. & Do not handle evidence with bare hand. \\
\hline
\end{tabular}

\subsection{Basic equipments (available in the form of kits) required for processing the scene of crime.}

(i) General crime scene investigation kit (ii) Crime scene protection kit (iii) Digital camera (iv) Forensic light source (v) Crime scene illumination kit (vi) Photo documentation kit (vii) Adhesive ID marker (viii) Evidence marker (ix) Gas mask (x) Explosive detection kit (xi) Narcotic detection kit (xii) Gunshot residue collection kit (xiii) Semen detection kit (xiv) Blood detection kit (xv) Impression evidence: Tyre and foot print investigation kit (xvi) Tool mark investigation kit (xvii) Arson investigation kit (xviii) Digital Evidence Collection tool kit (xix) Laptop (xx) Finger print lifting kit.

\subsection{Documentation of the crime scene}

The purpose of the observation and documentation of the crime scene is to make a note of the location of potential evidence and to mentally prepare and make an outline of how the crime scene will be examined. The crime scene conditions should be carefully observed and transient details, such as lighting (on/off), newspaper, on the door/in - house, curtains (open/closed), weather, temperature, movement of furniture, or other disturbances made in the life - saving efforts, conditions which would support or refute suicide/self - defense (gunshot residue, position of firearm in cases of shooting), etc. should be recorded. It is also important to be able to recognize what should be present at a scene of the crime but is not there, e. g. victim's purse, watch, ornaments, vehicle, etc. Similarly, the objects which appear to be out of place and might have been left by the perpetrator should be taken note of. If vehicles are involved in a crime, details of license (identification) number, the position of the key, gear shift position, meter reading, steering position, amount of fuel in the tank, lights turned on or off, etc. should be recorded. Use of the oblique lighting technique is a good technique to use indoors on hard floors. This technique only needed a suitable flashlight with a strong concentrated beam. Use this light just spreads over the floor surface and is almost parallel to the surface. The light is then moved back and forth. Any evidence, such as trace evidence and shoe prints, will appear dramatically which Under normal light conditions, this evidence may be barely visible or completely invisible. In addition to the floor, the ceiling should also be extensively inspected. It can get valuable evidence like blood splatter and bullet holes. Photography and videography may be used for the documentation of crime scene conditions. It can provide a better perspective on the crime scene layout. Photography and videography should begin with a general overview of the crime scene and the surrounding area, and it will cover the crime scene using wide - angle, close - up (long, middle, and close - up range) shots to show the shape, size, and position of the evidence and its relevance to the crime scene.

\section{Conclusion}

Crime scene investigation is a very important part of any investigation. It is the meeting point of science, logic and law. Physical evidence includes all objects that may establish or deny that a crime has been committed or link a crime with its perpetrator or victim. Forensic science begins at the crime scene. Here, investigators must identify the evidence for laboratory testing and preserve it properly. The primary duty of the first responding officer is securing the crime scene. Once the scene is secured, the relevant investigators record the crime scene taking photograph, making sketches and taking notes. Before processing the crime scene for physical evidence, the investigator should conduct a preliminary investigation of the scene as it was left by the offender. The search for physical evidence in a crime scene must be thorough and systematic. Typically the search pattern selected depends on the size of the scene and the locale and the number of collectors participating in the search. Physical evidence can be anything from huge objects to microscopic traces. Often, many items of evidence are clearly visible, but others can only be identified by examination in a crime laboratory. For this reason, in addition to the more obvious items, it is important to collect potential carriers such as clothing, vacuum sweeping, and cutting fingernails. Each different item or similar item collected in different places must be placed in a separate container. Packaging evidence individually prevents damage through contact and prevents cross - contamination. At the time of evidence collection, the chain of custody must be maintained a record indicating the location of the evidence. In addition, proper standard / reference samples, such as hair, a buccal swab, and fiber, must be collected from appropriate subjects for comparison at the crime scene and in the laboratory. The removal of any evidence from a person or crime scene must be carried out in accordance with the appropriate search and seizure protocol. Due to lack of scientific knowledge of the investigator regarding the proper collection, preservation, storage and transportation of crime scene evidence, failure to obtain appropriate analysis results and diminish its value before the court of law. Many factors contribute to the generation of a good report from a biological sample i.e. rate and extent of degradation, purity and amount of the sample, etc. "No biological evidence is resistant to degradation". Thus, careful collection and packing of crime scene evidence can provide useful information. Hence, proper precaution for collection and preservation of crime scene evidence is essential. Hope, this review will help to forensic, and law enforcement professionals to deal with crime scene evidence to avoiding contamination, degradation, and loss of the value of biological evidence.

\section{References}

[1] Nabar, B. S, Forensic Science - In criminal Investigation, $3^{\text {rd }}$ ed. Asia Law House - 2015 
[2] Sharma, B. R, Scientific Criminal Investigation, $2^{\text {nd }}$ ed. LexisNexis - 2018.

[3] Joe Nickell \& John F. Fisher, Crime Science - Methods of forensic detection, The University Press of Kentucky - 1998.

[4] Evans C, Criminal Investigation: Crime Scene Investigation, Chelser House Publisher - 2009.

[5] Crime Scene Investigation: A guide for law enforcement, National Forensic Science Technology Center (NFSTC) - 2013

[6] Fisher, Barry A. J. Techniques of Crime Scene Investigation, $7^{\text {th }}$ ed, CRC Press LLC - 2004.

[7] Houck, Max M. Forensic Science: Modern methods of solving crime. PRAEGER - 2007.

[8] Saferstein, R. Criminalisties: An introduction of forensic Science, $7^{\text {th }}$ ed - 2015.

[9] Bapuly, A. K, Forensic Science: Its Application in Crime Investigation, Paras Publication.

[10] Singh, H. N. (2021). Collection, preservation and transportation of biological evidence for forensic DNA analysis. www.ijaresm. com, 9 (9), 1123-1130.

[11] Everett Baxte JR, Complete Crime Investigation Handbook, CRC press - 2015.

[12] Gardner, Ross M. and Bevel T. Practical Crime Scene Analysis and Reconstruction, CRC press - 2009

[13] http: //aboutforensics. co. uk/edmond - locard/

[14] https: //www.legalserviceindia. com/legal/article 2974 - concept - and - principles - of - forensic science. html

[15] https: //en. wikipedia. org/wiki/Relevance

[16] https: //aceproject. org/ace en/topics/ei/eie/eie03/eie03d

[17] https: //en. wikipedia. org/wiki/Relevance

[18] https: //aceproject. org/ace en/topics/ei/eie/eie03/eie03d

[19] https: //www.crime - scene - investigator. net/evidenc2. html

[20] https: //ayalaforensics. wixsite. com/solvethemystery/crime - scene - documenting

[21] https: //www.crime - scene - investigator. net/newsletter/1010. html

[22] https: //www.coursehero. com/file/24413108/Examination - and Documentation - of - the - Crime - Scenedocx/

[23] Mwaheb, M. y Principles of crime Scene Investigation, Thesis · March 2019 